\title{
Endodontic management of maxillary first molar with two palatal canals.
}

\begin{abstract}
:
Having a thorough knowledge about the internal anatomy of a tooth and its possible variations is an important aspect for the success of a root canal therapy. Variations in the number of roots, root canals and configurations affect the treatment outcome. Moreover, missed canals make up for the highest chances of failure of endodontic therapy(1).

A maxillary first molar shows lot of variations in the anatomy. Although finding MB2 canal has now become a routine procedure, but variations in the palatal canal is still aberrant which concerns the clinicians. With the advancements in radiographic procedures, it has now become an easy task to look for aberrations in tooth anatomy. One such advancement is the Cone Beam Computed Tomography (CBCT) which acts as the third eye for clinicians. It helps in accurate diagnosis and in negotiating the complex morphologic variations in root canals(2).

This case report presents the endodontic management of a maxillary first molar presenting with five canals with two palatal canals confirmed with the aid of Cone Beam Computed Tomography.
\end{abstract}

Key words: Root canal therapy, Maxillary first molar, Two palatal canals, CBCT

\section{Introduction :}

Having a thorough knowledge about the internal anatomy of a tooth and its possible variations is an important aspect for the success of a root canal therapy. The success also depends on how accurately the anatomy is diagnosed and how well it is managed. In everyday practice, clinicians often encounter endodontic cases which present with challenges in establishing a diagnosis and treatment plan.

Human molars show varied anatomy regarding the number of roots and root canals. The literature outlines wide variations in root canal morphology of maxillary first molars wherein the frequency of two roots and two palatal canals is very low, i.e. $3.9 \%$ and $1 \%$ respectively $(3,4)$. Less variation is found in palatal root with only one canal in over $99 \%$ of the teeth studied(5).

Incidence of maxillary first molar with 2 separate palatal canals is extremely rare. Very few studies have reported their presence.

\begin{tabular}{|l|l|}
\hline \multicolumn{3}{|c|}{ Access this article online } \\
\hline \multirow{2}{*}{$\begin{array}{l}\text { Website: } \\
\text { www.ujds.in }\end{array}$} & Quick Response Code \\
\hline $\begin{array}{l}\text { DOI: } \\
\text { https://doi.org/10.21276/10.21276/ujds.2020.6.2.24 }\end{array}$ & \\
\hline
\end{tabular}

Holderrieth et al reported cases with two palatal canals in a single palatal root (6).

Conventional radiographs play a major role in determining the status of the concerned tooth. But they portray a 2-D image of a 3-D structure which limits its use in complex cases. Recent advancement in digital imaging is the invention of CBCT which provides with a thorough qualitative and quantitative examination of the tooth structure offering significant advantage in anatomical reconstruction of teeth $(6,7)$.

\footnotetext{
${ }^{1}$ THANVI C, ${ }^{2}$ RAISINGANI D, ${ }^{3}$ PRASAD AB, ${ }^{4}$ GATTANI S

1,2,3,4 Department of Conservative Dentistry and Endodontics Mahatma Gandhi Dental College and Hospital RIICO Industrial Area, Sitapura, Tonk Road, Jaipur, Rajasthan - 302022
}

Address for Correspondence: Dr. Charu Thanvi 505, Unique Aura, SahakarMarg, Lalkothi, Jaipur, Rajasthan - 302005 kusumvyas41164@gmail.com

Received : 7 April 2020, Published : 31 August 2020

How to cite this article: Charu Thanvi, Deepak Raisingani, Ashwani B. Prasaad, \& Saloni Gattani. (2020). Endodontic management of maxillary first molar with two palatal canals. UNIVERSITY JOURNAL OF DENTAL SCIENCES, 6(2):90-3 
The following case report delineates the endodontic management of a maxillary first molar with 5 canals: 2 mesiobuccal canals, 1 distobuccal canal and 2 separate palatal canals.

\section{Case Report:}

A 36 year old male patient visited the department of Conservative dentistry and Endodontics with the chief complaint of tooth decay in upper left back tooth region. On clinical examination, maxillary left first molar (\#26) revealed deep mesio-proximal caries which was non tender to percussion. Further evaluation with thermal and electric pulp sensitivity tests revealed no response. The radiographic finding showed deep mesio-proximal caries approaching pulp with widening of PDL space (Fig. 1). On correlating clinical and radiographic findings, tooth was diagnosed as necrotic pulp with asymptomatic apical periodontitis. The treatment plan was made as root canal therapy followed by coronal prosthesis.

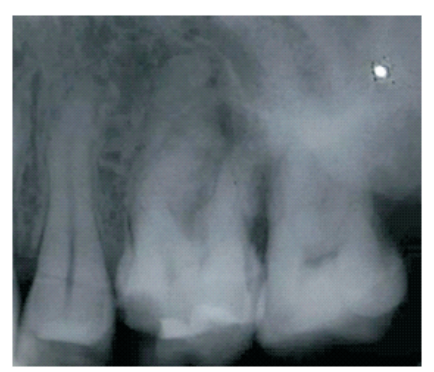

Fig. 1 Pre-op IOPA showing mesio-proximal caries approaching pulp with widening of PDL space \# 26

A thorough evaluation of IOPA with different angulations showed aberrant anatomy of palatal root appearing wider than usual, requiring further 3D evaluation of root canal anatomy before commencing endodontic therapy. CBCT evaluation showed two separate palatal canals in single root.(Fig. 2a \& $2 b)$.

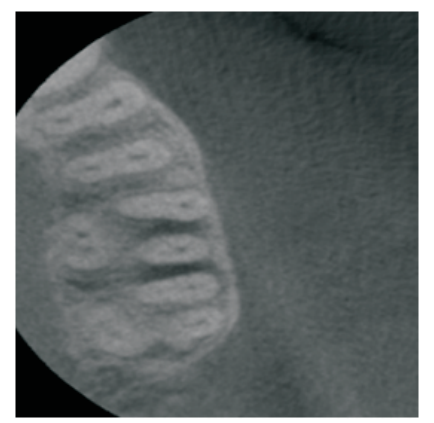

Fig. 2a CBCT imaging- Coronal section at apical third showing 2 separate palatal canals

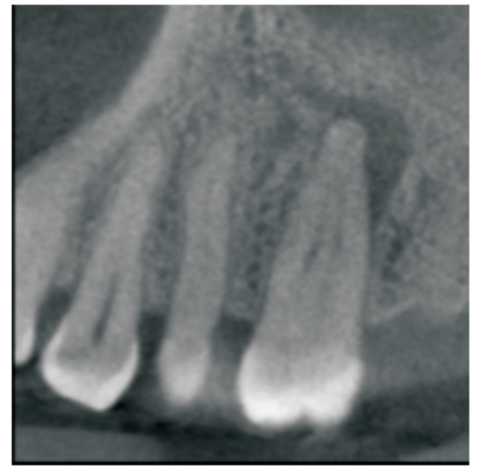

Fig. 2b CBCT imaging- Sagittal section of Palatal root indicating 2 completely separated palatal canals from coronal till apical one third

The endodontic therapy was then initiated. Tooth was anaesthetized with 2\% lidocaine with 1:200,000 epinephrine and access cavity was made with Endoaccess bur ( DentsplyMaillefer). Orifices were located with the help of DG-16 endodontic explorer (Hu-Friedy, Chicago, USA). The traditional trapezoidal shaped access cavity was modified by removing mesial shoulder connecting mesio buccal and palatal orifice revealing 5 orifices- two palatal, two mesio buccal and one distal (Fig. 3).

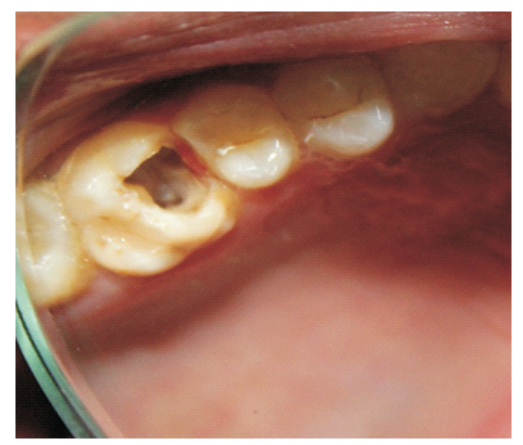

Fig. 3 Clinical picture showing 2 distinct palatal canal orifices.

Working length was established with $10 \mathrm{~K}$ file (Dentsply Maillefer, Switzerland) and cleaning \& shaping was done till $25,4 \%$ in mesio buccal and distobucaal canals and $20,6 \%$ in palatal canals by Hyflex CM rotary files (ColtenelWhaledent) using 15\% EDTA (Glyde, Dentsply Maillefer) with thorough irrigation by $5.25 \%$ of Sodium hypochlorite and copious saline.

The master cone fit was determined. Root canals were obturated with gutta percha along with AH Plus resin based root canal sealer (Dentsply Maillefer) followed by composite 
foundation (Fig. 4) and Porcelain Fused Metal (PFM) Tilite coronal prosthesis was delivered.

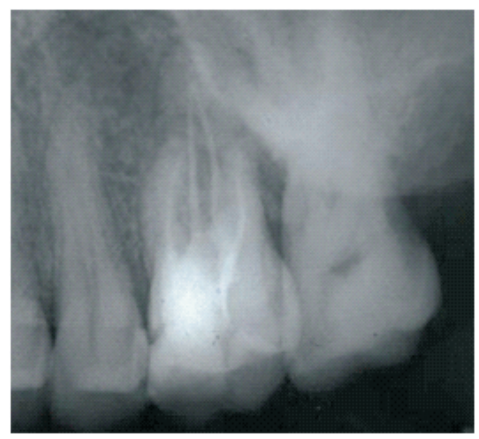

Fig. 4 IOPA-Obturationwith composite foundation \# 26

\section{Discussion:}

This case report outlines the basis of non-surgical endodontic management of a maxillary first molar with an anatomical variation in palatal root having 2 canals with Vertucci - Type IV and Weine - Type III root canal configuration confirmed with the help of CBCT.

In order to locate extra canals, clinician must have thorough knowledge about the anatomy as well as the variations associated with the particular tooth along with appropriate instruments and tools $(8,9)$.

Preoperative radiographs, 2-D radiographs from different angulations as well as 3-D imaging improve our visualization of root canal morphology.

Modification to the access cavity design are also necessary in order to locate additional canals. Maxillary molars having 2 palatal canals have a wider mesio-distal outline forming the shape of a square or trapezoid rather than a triangle.

In routine cases of endodontic therapy, we usually have a mental map regarding the anatomy of the roots $\&$ root canals. But often we encounter problem in locating additional canals with the same conventional access opening.

In necrotic tooth, dentinal dust frequently moves into an anatomical space, such as an orifice, fin or isthmus area forming a white dot or line which dragged our attention suggesting the presence of an extra canal in the palatal aspect of the chamber. However, in cases of vital tooth, red line test confirms the presence of additional canals by the flow of the blood at pulpal floor towards the location of the orifice.
Ultrasonic tips were a boon to finding extra canals as they prevent overcutting of dentin and reduced the risks of perforation.

Troughing around the potential location of canal loosen up the dentin overhang and open up the orifice. Micro-openers, DG16 \& JW-17 are some orifice openers which can locate a potential catch suggesting of an orifice location.

All these methods in addition with magnification via loupes or dental operating microscope definitely increase the frequency of locating additional canals as well as the successful outcome of the root canal therapy $(8,10)$.

Compared to 2-D radiographs, $\mathrm{CBCT}$ permits a more accurate diagnosis of the aberrant root canals with accurate identifications and measurements by slicing of images in multiple planes which otherwise may not be easily identifiable with conventional radiographs even if taken at different angles. Also the cone beam technique provides a $360^{\circ}$ scan of the concerned area assuring that no anatomic detail is missed which is otherwise quite frequent in conventional radiographic technique.

Failure to detect and treat a missed canal is an important cause for failure of endodontic treatment. The knowledge, awareness and understanding of the presence of unusual canal morphology during diagnosis and treatment phase of the teeth can contribute largely to a successful outcome of the treatment.

\section{Conclusion:}

An important factor in the success of an endodontic therapy is the ability to locate all the potential canals in the root canal system. Though the statistics prove the incidence of two palatal canals in a maxillary molar to be very low, it remains an important consideration to look for such variations so as to prevent mishaps and ensure successful long-term outcome of the root canal therapy.

\section{References:}

1. Hussain S, Kundabala M, Roma M. Maxillary First Molar with Two Palatal Canals: A Rare Case Report. Indian Journal of Public Health Research \& Development, 2018;9(1):181-184

2. Deepalakshmi M, Miglani R, Indira R, Ramachandran S. Spiral CT diagnosis and 
endodontic management of an anatomically variant palatal root with two canals in a maxillary first molar. Indian J Dent Res 2010;21:443-5

3. Favieri A, Barros FG, Campos LC. Root canal therapy of a maxillary first molar with five root canals: Case report. Braz Dent J 2006; 17(1):75-8

4. Cleghorn BM, Christie WH, et al. Root and root canal morphology of the human permanent maxillary first molar: A literature review. J Endod2006;32:813-20

5. Ingle JI, Bakland L, J. Craig Baumgartner. Endodontics 2008;6:174-177

6. Kharbanda A, Bali R, Singh PH, Aberrant canal configuration of the maxillary first molar: a case report. Journal of Oral Health and Dental Management 2015; 14(6) :334-336

7. Holderrieth $\mathrm{S}$, Gernhardt CR. Maxillary molars with morphologic variations of the palatal root canals: A report of four cases. J Endod 2009;35: 1060-5

8. Gopikrishna V, Reuben J, Kandaswamy D. Endodontic management of a maxillary first molar with two palatal roots and a single fused buccal root diagnosed with spiral computed tomography: A case report. Oral Surg Oral Med Oral Pathol2008;105:74-8

9. Mohammadi, Zahed, et al. "A Clinical Update on the Different Methods to Decrease the Occurrence of Missed Root Canals." Iranian endodontic journal 2016;11(3): 208-13

10. Stephen J. Unusual maxillary first molars with two palatal canals within a single root. J Can Dent Assoc 2001;67:211-3 